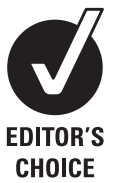

CHOICE
Division of Respiratory Disease Studies, National Institute for Occupational Safety and Health, Centers for Disease Control and Prevention, Morgantown, West Virginia, USA

\section{Correspondence to A Scott Laney, Surveillance Branch, Division of Respiratory Disease Studies, National Institute for Occupational Safety and Health, Centers for Disease Control and Prevention, 1095 Willowdale Road, Mail Stop HG900.2, Morgantown, W V 26505-2888, USA; alaney@cdc.gov}

The findings and conclusions in this report are those of the authors and do not necessarily represent the views of The National Institutes for Occupational Safety and Health.

Accepted 19 July 2009 Published Online First 22 September 2009

\title{
Pneumoconiosis among underground bituminous coal miners in the United States: is silicosis becoming more frequent?
}

\author{
A Scott Laney, Edward L Petsonk, Michael D Attfield
}

\section{ABSTRACT}

Objectives Epidemiological reports since 2000 have documented increased prevalence and rapid progression of pneumoconiosis among underground coal miners in the United States. To investigate a possible role of silica exposure in the increase, we examined chest $x$-rays (CXRs) for specific abnormalities (r-type small opacities) known to be associated with silicosis lung pathology. Methods Underground coal miners are offered CXRs every 5 years. Abnormalities consistent with pneumoconiosis are recorded by National Institute for Occupational Safety and Health (NIOSH) B Readers using the International Labour Organization Classification of Radiographs of Pneumoconioses. CXRs from 1980 to 2008 of 90973 participating miners were studied, focussing on reporting of r-type opacities (small rounded opacities 3-10 mm in diameter). Log binomial regression was used to calculate prevalence ratios adjusted for miner age and profusion category. Results Among miners from Kentucky, Virginia and West Virginia, the proportion of radiographs showing rtype opacities increased during the 1990s (prevalence ratio (PR) 2.5; 95\% Cl 1.7 to 3.7) and after 1999 (PR 4.1; $95 \% \mathrm{Cl} 3.0$ to 5.6), compared to the 1980s (adjusted for profusion category and miner age). The prevalence of progressive massive fibrosis in 2000-2008 was also elevated compared to the 1980s (PR 4.4; 95\% Cl 3.1 to 6.3) and 1990s (PR 3.8; 95\% Cl 2.1 to 6.8) in miners from Kentucky, Virginia and West Virginia.

Conclusions The increasing prevalence of pneumoconiosis over the past decade and the change in the epidemiology and disease profile documented in this and other recent studies imply that US coal miners are being exposed to excessive amounts of respirable crystalline silica.

\section{INTRODUCTION}

Underground coal miners are at risk of developing coal workers' pneumoconiosis (CWP), and to a lesser extent, silicosis, both being progressive and potentially fatal interstitial lung diseases. ${ }^{1}{ }^{2}$ The prevalence of pneumoconiosis among working underground coal miners in the United States declined progressively from 1970 to 2000 as a result of federal restrictions on respirable dust concentrations in underground coal mines enacted in 1969. ${ }^{3-5}$ However, since 2000 the decreasing trend appears to have reversed and the prevalence of pneumoconiosis among examined miners with 15 or more years of coal-mining tenure has increased markedly. ${ }^{6}$ In addition to the increasing prevalence, recent reports suggest changes in the epidemiology and clinical features of pneumoconiosis among

\section{What this paper adds}

- Epidemiologic reports since 2000 have documented increased prevalence and rapid progression of pneumoconiosis among underground coal miners in the United States.

- This study found an increase in a specific type of radiographic abnormality that has been shown to be associated with silicosis lung pathology.

- The increasing prevalence of r-type opacities, and greater number of cases of severe disease found in this study within the Appalachian coal fields point to excessive exposures to crystalline silica, a long recognized cause of rapid disease progression and severe pneumoconiosis in coal miners.

- These findings stress the need for a timely, comprehensive, accurate, and ongoing evaluation of crystalline silica exposures and control strategies in underground coal mines throughout the United States.

underground coal miners, characterised by an increase in severity, geographical clustering, rapid disease progression and advanced disease in younger miners. ${ }^{7-9}$

Since 1980, national mean exposure levels of respirable mixed coal mine dust reported for enforcement purposes have been consistently below federal permissible exposure limits and relatively unchanged on an annual basis. In the face of the established aetiological association of CWP with coal mine dust, and the reported stability in miners' exposures to respirable mine dust over the last three decades, we sought additional explanations for the current increasing disease trend and changing clinical pattern.

One potential explanation is that the toxicity of the dust generated during coal mining has changed, resulting in an increased inflammatory response and more potent induction of pneumoconiosis. An increased proportion of crystalline silica in coal mine dust provides a plausible explanation for an increase in dust toxicity. ${ }^{10}$ Some underground coal mining jobs are known to be associated with silica exposure, and the lungs of a minority of coal miners have been demonstrated to show typical pathological lesions of silicosis. ${ }^{2} 1011$ Additionally, rapid progression $^{9}$ and progressive massive fibrosis $(\mathrm{PMF})^{10} 12$ are more likely with silicosis than with CWP. ${ }^{11}$ 
To investigate the potential role of dusts containing free silica in the increasing prevalence and severity of dust-related lung disease in coal miners, we examined radiographs from underground coal miners for the presence of a specific type of abnormality that has been shown to be associated with silicosis lung pathology (rounded pneumoconiotic opacities exceeding $3 \mathrm{~mm}$-r-type). Using data from miners who participated from 1980 to 2008 in the National Institute for Occupational Safety and Health (NIOSH)-administered Coal Workers' X-ray Surveillance Program (CWXSP), we report the time trends and geographical distribution of these radiographic abnormalities.

\section{METHODS}

Data were derived from the CWXSP. Characteristics of the surveillance program, including data collection, historical perspectives, institutional review board approval and patient consent, have been extensively described elsewhere. ${ }^{4}{ }^{13}{ }^{14}$ In brief, all US underground coal miners are eligible, and those that participate complete a standardised questionnaire documenting age, sex and employment history, and undergo a chest radiograph approximately every 5 years. The radiographs are classified by NIOSH B Readers for the presence, profusion and type of lung parenchymal abnormalities consistent with pneumoconiosis, according to the International Labour Organization Classification of Radiographs of Pneumoconioses (ILO Classification) ${ }^{15}$ and results are recorded in a standardised format. ${ }^{16}$ Under the ILO Classification, small pneumoconiotic opacities are scored as category 0 (absent) or categories 1,2 or 3 profusion as the disease severity increases. In addition, the opacities are categorised by their shape and size (type) under the ILO Classification. ${ }^{15}$ Large opacities are similarly recorded as categories A, $\mathrm{B}$ and $\mathrm{C}$. PMF was defined as the presence of any large opacity.

Data for the present analysis were restricted to radiographs of underground coal miners acquired from 1 January 1980 to 15 September 2008. For inclusion in the analytical dataset, an ILO Classification complying with NIOSH program procedures, as well as complete information regarding mine location, date of birth and date of the radiograph, were required. Because the CWXSP is an ongoing health surveillance program, many miners had multiple radiographic readings recorded over time. For the present analysis, data were restricted to the most recent classification of the most recent radiograph available for each individual.

The presence of r-type opacities on a miner's radiograph was determined from the primary and secondary shape and size of small pneumoconiotic opacities designated by the NIOSH B Reader on the standard Roentgenographic Interpretation Form. ${ }^{16}$ A radiograph was determined to show r-type opacities when the classification indicated r-type for either the primary or secondary opacity type. Mining tenure was not available for all miners, however a date of birth for each miner was provided. Sub-analyses indicated mining tenure was correlated with miner age. Prevalence ratios (PR) were adjusted for profusion category and median age using log binomial regression. The SAS statistical software package V.9.1 (SAS Institute, Cary, North Carolina, USA) was used for all analyses.

In total, 31 different B Readers contributed $98 \%$ of the total readings from 1980 to 2008. However, different readers participated in the CWXSP for various time periods, with 14 readers participating in more than one decade and four reading for the full period of this investigation. To understand any timedependent reader effects on the results, we examined the findings after grouping readers by the decade or decades during which they classified study radiographs.

\section{RESULTS}

\section{Mining population}

Classifications for 90973 miners from 1980 to 2008 (any mining tenure) were included in the analysis. The majority were male (97\%) and white (96\%), and 50.7\% were mining in Kentucky, Virginia or West Virginia at the time the radiograph was obtained. Of the 90973 radiographs, 2868 (3.2\%) had a profusion determination of ILO category 1 or greater. Median miner age (in years) at the time of the radiograph was 32.5 for 1980-1989 compared to 42.8 and 44.3 for the 1990-1999 and 2000-2008 time periods, respectively.

\section{Radiographic small opacity profusion}

Of the 2868 radiographs taken in 1980-2008 and showing ILO category 1 or greater small opacities, $85.7 \%$ showed category 1 , $12.3 \%$ showed category 2 and $2.0 \%$ category 3 . The distribution of small opacity profusion classifications for the study population is presented in table 1 by decade. The proportion of radiographs showing category 0 or 1 varied little over the study period. In contrast, since 2000 there has been a $28 \%$ increase in category 2 , and a greater than twofold increase in category 3 classifications compared to 1980-1999 (prevalence ratio (PR) 2.4; 95\% CI 1.4 to 4.0; Fisher $\mathrm{p}=0.001$ ) (table 1 ).

When stratified by region, a marked increase over time in the proportion of small opacity profusion categories 2 and 3 is apparent among miners in Kentucky, Virginia and West Virginia, although not in the remainder of the United States (figure 1). Specifically, since 1999, radiographs showing opacity profusion categories 2 and 3 have become over twice as common compared to 1980-1999 (PR 2.3; 95\% CI 1.8 to 2.9) in Kentucky, Virginia and West Virginia. In contrast, in the remainder of the USA, the proportion of radiographs with categories 2 and 3 opacity profusion appears to have decreased over time (PR 0.66; 95\% CI 0.42 to 1.0$)$.

\section{Progressive massive fibrosis}

The prevalence of PMF in the USA has increased since 1999 compared to 1980-1999 (PR 2.2; 95\% CI 1.6 to 3.0; Fisher $\mathrm{p}<0.0001)$. However, similar to the trend observed for small opacity profusion category, outside of Kentucky, Virginia and West Virginia, PMF has declined in the last three decades (figure 2). The prevalence of PMF between the 1980s and 1990s did not significantly differ. However, in Kentucky, Virginia and West Virginia the prevalence of PMF in 2000-2008 was elevated compared to the 1980s (PR 4.4; 95\% CI 3.1 to 6.3) and $1990 \mathrm{~s}$ (PR 3.8; 95\% CI 2.1 to 6.8).

\section{r-Type opacities}

r-Type opacities were noted as the primary shape/size for 201 radiographs, representing $0.22 \%$ of the total radiographs. A similar finding was observed for the secondary r-type opacities,

Table 1 Small opacity profusion and progressive massive fibrosis among participants in the NIOSH Coal Workers' X-ray Surveillance Program, 1980-2008

\begin{tabular}{|c|c|c|c|c|}
\hline \multirow[b]{2}{*}{ Year } & \multicolumn{3}{|c|}{ Small opacity profusion category } & \multirow{2}{*}{$\begin{array}{l}\text { Large } \\
\text { opacity } \\
\text { PMF }\end{array}$} \\
\hline & 0 & 2 & 3 & \\
\hline
\end{tabular}

$1980-1989(\mathrm{n}=46928) \quad 45437(96.8) \quad 1303(2.8) \quad 168(0.36) \quad 20(0.04) \quad 68(0.14)$ $1990-1999(\mathrm{n}=15564) \quad 15100(97.0) \quad 402(2.6) \quad 55(0.35) \quad 7(0.04) \quad 21(0.13)$ $2000-2008(n=28481) \quad 27568(96.8) \quad 754(2.7) \quad 130(0.46) \quad 29(0.10) \quad 91(0.32)$

Data are numbers (\%). PMF includes category $A, B$ and $C$ opacities. $\mathrm{NIOSH}$, National Institute for Occupational Safety and Health; PMF, progressive massive fibrosis. 


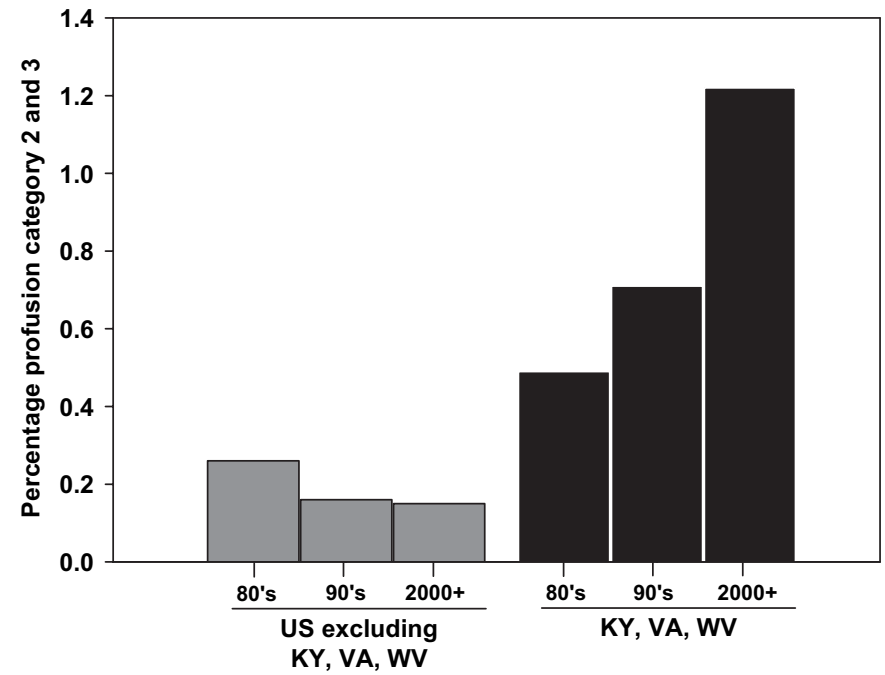

Figure 1 Pneumoconiosis small opacity category 2 and 3 by region and decade, 1980-2008.

which comprised $0.21 \%$ of the total radiographs. The 321 radiographs $(0.35 \%)$ classified as showing r-type opacities (primary and/or secondary type) are the focus of the subsequent analyses.

The proportion of radiographs showing r-type opacities increased over time since 1980. Simple linear regression of the percentage of radiographs showing r-type opacities per year between 1980 and 2008 yielded a regression coefficient of 0.02 and $p$ value of $<0.0001$. For the United States overall, there has been a 3.7-fold increase in r-type opacities among miners with radiographs taken after 1999, compared to 1980-1989 (PR 3.7; $95 \%$ CI 2.8 to 4.7$)$, and a twofold increase compared to 1990-1999 (PR 2.0; 95\% CI 1.5 to 2.7).

When stratified by region, the overall national increase observed in r-type opacities is diminished when data from Kentucky, Virginia and West Virginia are excluded. This suggests that a substantial portion of the effect observed at the national level is driven by the regional contribution of Kentucky, Virginia and West Virginia. In fact, for the three-state region, there has been a 7.6-fold increase (95\% CI 5.5 to 10.2) in the proportion of r-type opacities observed in 2000-2008 compared to the 1980s (figure 3). We found no statistical difference among any other specific opacity type ( $\mathrm{p}, \mathrm{q}, \mathrm{s}, \mathrm{t}, \mathrm{u})$ over time.

\section{Adjustment for small opacity profusion and reader}

It may be that the likelihood of reporting r-type opacities increases with increasing small opacity profusion category, independent of the presence of silicosis. When all the study radiographs were analysed together, increasing small opacity profusion category was associated with progressively greater percentage of the radiographs showing r-type opacities (table 2). However, increasing profusion over time in the three-state region does not fully account for the overall increase observed in r-type opacities. Since 1999, the proportion of r-type opacities increased within every profusion category among all participating US coal miners (table 2).

In fact, r-type opacities increased significantly over time, even accounting for the effect of profusion category and region. Overall, the proportion of radiographs showing r-type opacities increased nearly twofold in the 1990s (PR 1.7; 95\% CI 1.2 to 2.3 ) and threefold after 1999 (PR 3.1; 95\% CI 2.4 to 4.1), compared to the 1980s, after adjusting for profusion category and miner age (table 3). A significant increase was observed in the proportion of r-type opacities between the 1980s and 1990s and between the 1990s and 2000-2008 in Kentucky, Virginia and West Virginia (table 3). Since 1999, a greater than 1.5-fold increase has occurred both regionally and nationally (table 3 ).

An apparent increase in reporting of r-type opacities could have arisen because different readers were employed over time in the CWXSP. If the readers employed at different times differed systematically in their predilections for reporting r-type opacities, it could have given rise to an artifactual temporal increase. This was explored by analysing the data by groups of readers corresponding to the decade or decades during which they read for the CWXSP. Importantly, the overall observed trend was evident in the sub-group of readers who read during all three decades. Here the PRs were 2.1 for the 1990s to 2000-2008 and 3.6 for 1980s to 2000-2008, virtually identical to those reported earlier of 2.2 and 3.7 for the whole dataset.

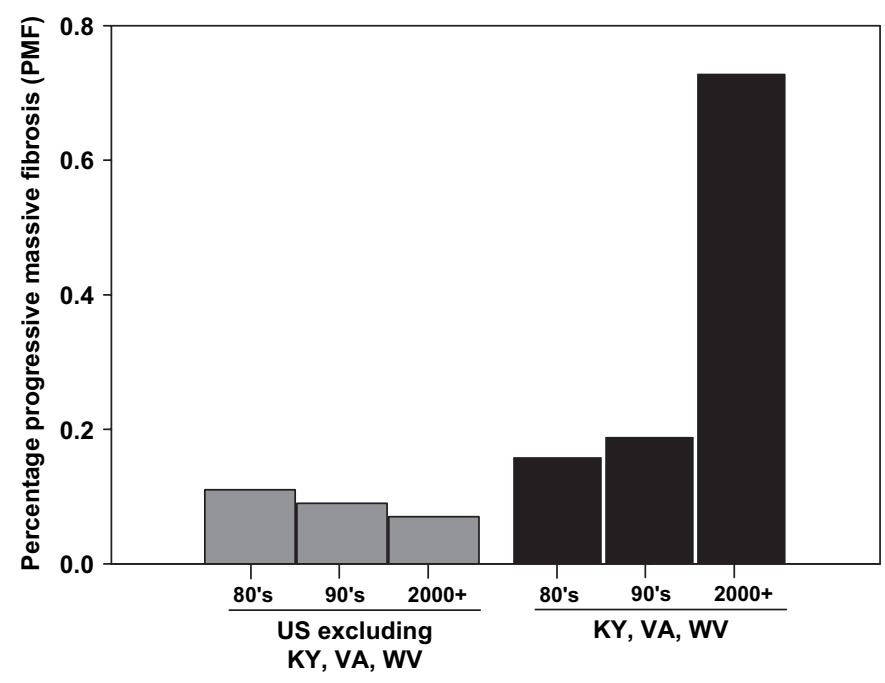

Figure 2 Progressive massive fibrosis by region and decade, 1980-2008.

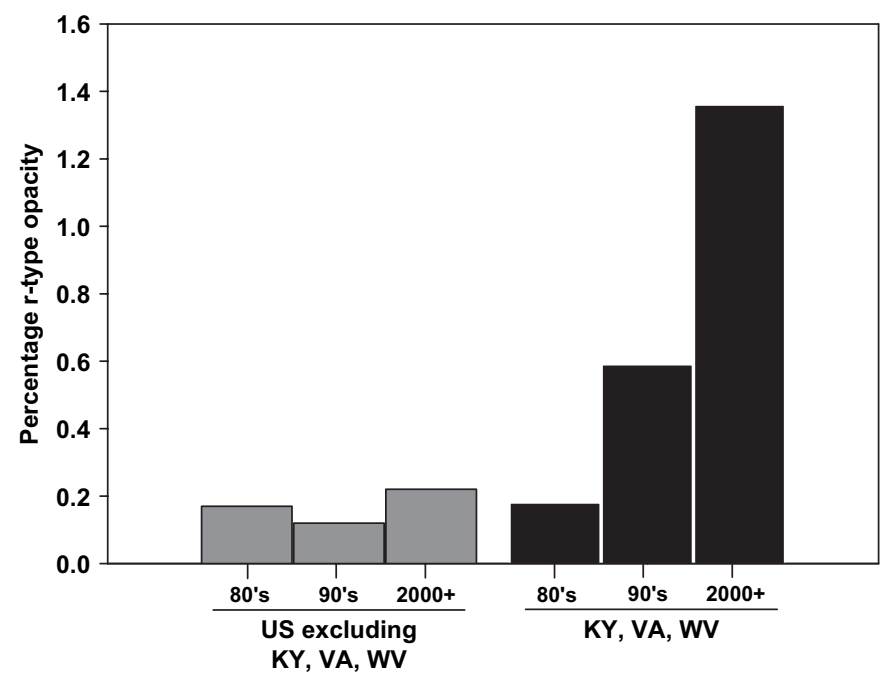

Figure 3 Percentage of r-type opacities by region and decade, 1980-2008. 
Table 2 Prevalence of r-type opacities among participants in the NIOSH Coal Workers' X-ray Surveillance Program by small opacity profusion category, 1980-2008, any tenure

\begin{tabular}{llll}
\hline \multirow{4}{*}{ Year } & \multicolumn{3}{l}{ Small opacity profusion category } \\
\cline { 2 - 4 } $\mathbf{0}$ & $\mathbf{1}$ & $\mathbf{2}$ or $\mathbf{3}$ \\
\hline $1980-1989$ & $0.02 \%(8 / 45444)$ & $3.5 \%(45 / 1303)$ & $16.5 \%(31 / 188)$ \\
$1990-1999$ & $0.02 \%(3 / 15106)$ & $7.2 \%(29 / 403)$ & $30.6 \%(19 / 62)$ \\
$2000-2008$ & $0.08 \%(23 / 27493)$ & $12.4 \%(95 / 765)$ & $43.0 \%(68 / 158)$
\end{tabular}

Category 0 includes borderline abnormality (ie, $0 / 1$ )

NIOSH, National Institute for Occupational Safety and Health.

\section{DISCUSSION}

The prevalence of r-type pneumoconiotic opacities on the radiographs of US underground coal miners has increased markedly since 1999. This is most apparent among miners in Kentucky, Virginia and West Virginia. This finding is not explained by any changes in the readers employed over time, nor by the concurrent reported increase in pneumoconiosis severity.

Miners with r-type opacities often demonstrate classical silicotic nodules on lung pathology, ${ }^{1}$ and autopsy studies have shown that the lungs of coal workers with r-type opacities contain the highest levels of non-combustible ash consistent with silica. ${ }^{17} 18$ Because the latency for pneumoconiosis is generally 10 or more years after the onset of exposure, the study results suggest a marked increase in the exposure of coal miners to respirable silica during the last $30-40$ years.

Based upon the data available, we were unable to establish a specific exposure mechanism to account for our observations. However, over the last four decades there have been changes in coal demand, accessibility and mining technology that could potentially explain increasing respirable silica exposure in coal mines. US coal consumption has increased $62 \%$ since 1980 , reaching 1129 million short tons consumed in 2007. ${ }^{19}$ The continuous rise in the demand for coal, coupled with increasingly productive mining equipment, has led to the depletion of the largest, most easily accessible North American underground coal seams. ${ }^{20}$ These factors, and the increasing price of energy sources, have made mining thinner seams of coal more economically feasible. US thin seam coal mines (less than 43 inches) are almost exclusively located in the Appalachian bituminous coal fields. In fact, $96 \%$ of US thin seam mines are located in Kentucky, Virginia and West Virginia. ${ }^{21}$

Crystalline silica is commonly found in the rock strata surrounding coal seams, in concentrations much higher than within the coal seam itself. ${ }^{22}$ The risk of breaching the coal/ rock interface is greater in thin coal seams and is likely associated with greater waste rock mined. However, from the economic perspective, the increased mining of waste rock has been offset by improved coal cleaning technologies, allowing

Table 3 Prevalence ratios and 95\% Cls of r-type opacities among participants in the NIOSH Coal Workers' X-Ray Surveillance program, 1980-2008, any tenure

\begin{tabular}{|c|c|c|c|}
\hline & \multicolumn{3}{|c|}{ Prevalence ratios and $95 \% \mathrm{Cl}$} \\
\hline & 1990s vs $1980 \mathrm{~s}$ & $2000+$ vs $1990 s$ & $2000+$ vs $1980 \mathrm{~s}$ \\
\hline $\begin{array}{l}\text { USA except Kentucky, } \\
\text { Virginia, West Virginia }\end{array}$ & $1.0(0.49$ to 1.8$)$ & $1.6(0.86$ to 3.0$)$ & 1.5 (1.0 to 2.4$)$ \\
\hline $\begin{array}{l}\text { Kentucky, Virginia, } \\
\text { West Virginia }\end{array}$ & $2.5(1.7$ to 3.7$)$ & $1.6(1.2$ to 2.2$)$ & $4.1(3.0$ to 5.6$)$ \\
\hline All USA & 1.9 (1.3 to 2.7$)$ & $1.7(1.2$ to 2.3$)$ & $3.1(2.4$ to 4.1$)$ \\
\hline
\end{tabular}

Log binomial regression was used for miner age and small opacity profusion adjustments. Prevalence ratios were calculated separately for each region. Models were of the form: $r$ type opacity $=\alpha+\beta_{1(1990 \mathrm{~s})}+\beta_{2(2000+)}+\beta_{3(\text { Profusion category } 0)}+\beta_{4(\text { Profusion category 1) }}+\beta_{5}$ (Profusion category 2) $+\beta_{5 \text { (Age) }}$. for more cost-efficient removal of non-combustible by-products (particularly siliceous rock) in lower quality run-of-the-mine coal. The trends in mining practices and the geographical location of thin seam mining provide a plausible explanation for an increasing exposure to silica dust implied by the results of this study.

To explain the study findings, we would anticipate that the mean exposure to respirable silica would have increased since 1980. Paradoxically, the mean levels of respirable crystalline silica reported for compliance purposes do not demonstrate an increasing trend over that time. ${ }^{6}$ However, the compliance method for controlling silica exposure in coal mining has been criticised. $^{23} 24$ Instead of monitoring silica levels directly and ensuring enforcement on that basis, the procedure is indirect and complicated, involving a reduction in the overall coal mine dust compliance standard depending on past measurements of the quartz percentage. This has been said to result in inadequate enforcement. $^{23} 24$ Others have criticised the enforcement approach for coal mine dust, upon which the current silica compliance approach is based. ${ }^{25-28}$ Currently, NIOSH recommends that exposure to respirable quartz dust be limited to $0.05 \mathrm{mg} / \mathrm{m}^{3}$, measured and enforced directly during the work shift.

This study has focused specifically on silica exposure and its possible role in the increase in extent and severity of pneumoconiosis in the USA and selected states. However, other factors, such as increased production (implying an increase in general coal mine dust exposures) and increasing hours worked, may have contributed to the observed increases in disease. However, it does seem likely that the previous reports of geographical clustering of rapidly progressing CWP in younger miners, ${ }^{7-9}$ the increasing prevalence of r-type opacities, and the greater number of cases of severe disease found in this study within the Appalachian coal fields point to excessive exposures to crystalline silica, a long recognised cause of rapid disease progression ${ }^{11}$ and severe pneumoconiosis in coal miners. ${ }^{10} 12$ Taken together, these findings stress the need for a timely, comprehensive, accurate and ongoing evaluation of crystalline silica exposures and control strategies in underground coal mines throughout the United States.

Acknowledgements The authors would like to thank the Coal Workers' Health Surveillance Program team under the leadership of Anita Wolfe.

Funding The National Institute for Occupational Safety and Health provided funding for this study.

Competing interests None.

Patient consent Obtained.

Ethics approval This study was conducted with the approval of The National Institute for Occupational Safety and Health.

Provenance and peer review Not commissioned; externally peer reviewed.

\section{REFERENCES}

1. Soutar CA, Collins HP. Classification of progressive massive fibrosis of coalminers by type of radiographic appearance. Br J Ind Med 1984;41:334-9.

2. Castranova V, Vallyathan V. Silicosis and coal workers' pneumoconiosis. Environ Health Perspect 2000;108(Suppl 4):675-84.

3. Attfield MD, Althouse RB. Surveillance data on US coal miners' pneumoconiosis, 1970 to 1986. Am J Public Health 1992;82:971-7.

4. Attfield MD, Castellan RM. Epidemiological data on US coal miners' pneumoconiosis, 1960 to 1988. Am J Public Health 1992;82:964-70.

5. Attfield MD, Seixas NS. Prevalence of pneumoconiosis and its relationship to dust exposure in a cohort of U.S. bituminous coal miners and ex-miners. Am J Ind Med 1995;27:137-51

6. National Institute for Occupational Safety and Health. Work-related lung disease surveillance report 2007. In: Division of Respiratory Disease Studies, ed. Morgantown: Department of Health and Human Services, 2008:41-3. 
7. Centers for Disease Control and Prevention. Advanced cases of coal workers' pneumoconiosis-two counties, Virginia, 2006. MMWR Morb Mortal Wkly Rep 2006;55:909-13.

8. Centers for Disease Control and Prevention. Advanced pneumoconiosis among working underground coal miners-eastern kentucky and southwestern Virginia, 2006. MMWR Morb Mortal Wkly Rep 2007:56:652-5.

9. Antao VC, Petsonk EL, Sokolow LZ, et al. Rapidly progressive coal workers' pneumoconiosis in the United States: geographic clustering and other factors. Occup Environ Med 2005:62:670-4.

10. Jacobsen $\mathbf{M}$, Maclaren WM. Unusual pulmonary observations and exposure to coal mine dust: a case-control study. Ann Occup Hyg 1982;26:753-65.

11. Seaton A, Dick JA, Dodgson J, et al. Quartz and pneumoconiosis in coalminers. Lancet 1981;2:1272-5.

12. Hurley JF, Burns J, Copland L, et al. Coalworkers' simple pneumoconiosis and exposure to dust at 10 British coalmines. $\mathrm{Br} \mathrm{J}$ Ind Med 1982:39:120-7.

13. Centers for Disease Control and Prevention. Pneumoconiosis prevalence among working coal miners examined in federal chest radiograph surveillance programs-United States, 1996-2002. MMWR Morb Mortal Wkly Rep 2003:52:336-40.

14. Centers for Disease Control and Prevention. Pneumoconiosis in coal miners: NIOSH research and surveillance. MMWR Morb Mortal Wkly Rep Surveill Summ 1983; 32:39SS-42SS

15. International Labour Organization. Guidelines for the use of the ILO international classification of radiographs of pneumoconiosesed. Geneva: International Labour Organization, 2002.

16. National Institute for Occupational Safety and Health. Roentgenographic interpretation form. Morgantown: NIOSH, 2000. http://www.cdc.gov/niosh/pdfs/cdc-niosh-2.8.pdf.

17. Fernie JM, Ruckley VA. Coalworkers' pneumoconiosis: correlation between opacity profusion and number and type of dust lesions with special reference to opacity type. Br J Ind Med 1987;44:273-7.
18. Ruckley VA, Fernie JM, Chapman JS, et al. Comparison of radiographic appearances with associated pathology and lung dust content in a group of coalworkers. Br J Ind Med 1984;41:459-67.

19. Energy Information Administration. Annual Energy Review 2007. In: Department of Energy, ed. Washington, DC, 2007.

20. Energy Information Administration Office of Coal Nuclear Electric and Alternate Fuels. Quarterly Coal Report April-June 2008. In: US Department of Energy, ed. Washington, DC, 2008.

21. Peters RH, Fotta B, Mallett LG. The influence of seam height on lost-time injury and fatality rates at small underground bituminous coal mines. Appl Occup Environ Hyg 2001;16:1028-34.

22. Page SJ. Comparison of coal mine dust size distributions and calibration standards for crystalline silica analysis. AlHA J (Fairfax, Va) 2003;64 30-9.

23. Corn M, Breysse P, Hall T, et al. A critique of MSHA procedures for determination of permissible respirable coal mine dust containing free silica. Am Ind Hyg Assoc J 1985:46:4-8.

24. Villnave JM, Corn $\mathbf{M}$, Francis $\mathrm{M}$, et al. Regulatory implications of airborne respirable free silica variability in underground coal mines. Am Ind Hyg Assoc $\mathrm{J}$ 1991;52:107-12

25. Boden LI, Gold M. The accuracy of self-reported regulatory data: the case of coal mine dust. Am J Ind Med 1984;6:427-40.

26. Seixas NS, Robins TG, Rice CH, et al. Assessment of potential biases in the application of MSHA respirable coal mine dust data to an epidemiologic study. Am Ind Hyg Assoc J 1990;51:534-40.

27. Weeks JL. Tampering with dust samples in coal mines (again). Am J Ind Med 1991;20:141-4.

28. Weeks JL. The fox guarding the chicken coop: monitoring exposure to respirable coal mine dust, 1969-2000. Am J Public Health 2003:93:1236-44.

\section{The OEM Blog}

We are pleased to announce the initiation of the Occupational \& Environmental Medicine blog, available at http://blogs.bmj.com/oem/. The OEM blog is edited by Dr. Leslie Elliott. It's our hope that the blog will serve the occupational and environmental health community as a forum for discussion and debate of current issues in the field. We welcome a wide range of relevant contributions, including comments on articles published in the Journal, discussion of developments of interest to researchers and practitioners, novel observations and ideas for research, news, and announcements. Contributions to the OEM blog are not peer reviewed, but are screened for relevance and appropriateness and may be edited before posting. As with other correspondence with the Journal, we reserve the right to decline contributions, and we cannot publish material that is offensive, libelous or illegal. As this is a new medium for OEM, we expect that the blog will develop in its own way as the community begins to use it.

Dana Loomis

Leslie Elliott 